\title{
Usefulness of the SYNTAX and Clinical SYNTAX Scores in Predicting Clinical Outcome After Unrestricted Use of Sirolimus- and Everolimus-Eluting Stents
}

\author{
Kyung Woo Park, MD, PhD; Jeehoon Kang, MD; Si-Hyuck Kang, MD; Hyo-Suk Ahn, MD; \\ Hae-Young Lee, MD, PhD; Hyun-Jae Kang, MD, PhD; Bon-Kwon Koo, MD, PhD; \\ In-Ho Chae, MD, PhD; Tae-Jin Youn, MD, PhD; Byung-Hee Oh, MD, PhD; \\ Young-Bae Park, MD, PhD; David E. Kandzari, MD; Hyo-Soo Kim, MD, PhD
}

\begin{abstract}
Background: The SYNTAX score (SS) and clinical SS (cSS) can assess coronary lesion complexity and are useful indices in predicting outcomes after percutaneous coronary intervention. However, their validity has not been fully investigated in daily practice where "limus"-eluting stents are used.
\end{abstract}

Methods and Results: The SS and cSS were independently assessed from the Efficacy of Xience/Promus vs. Cypher in rEducing Late Loss after stENTing (EXCELLENT) registry, together with the 1-year patient-oriented composite endpoint (POCE; all-cause death, any myocardial infarction (MI), and any revascularization) and target-lesion failure (TLF; cardiac death, target-vessel MI, and target-lesion revascularization). Among 5,102 patients, tertiles for SS were defined as low-SS $<8,8 \leq$ mid-SS $\leq 16$, high-SS $>16$. Both POCE $(4.2 \%$ vs. $7.7 \%$ vs. $12.2 \%, P<0.001)$ and TLF (1.6\% vs. $2.4 \%$ vs. $4.5 \%, \mathrm{P}<0.001)$ increased significantly with increasing SS tertile, and SS was an independent predictor of POCE $(P<0.001$ for trend) and TLF $(P=0.023$ for trend $)$ in multivariate analysis. The predictability of $S S$ and cSS was similar for POCE (area under the curve (AUC): 0.635 vs. $0.629, P=0.599$ ), whereas SS was superior in predicting restenosis-related outcomes such as revascularization (AUC: 0.624 vs. $0.577, \mathrm{P}<0.001$ ) and cSS was superior in other components such as death (AUC: 0.654 vs. $0.795, \mathrm{P}<0.001$ ).

Conclusions: Both SS and cSS were applicable to unrestricted use of "limus"-eluting stents in predicting the risk of 1-year clinical outcomes. (Circ J 2013; 77: 2912-2921)

Key Words: Angiography; Drug-eluting stents; Percutaneous coronary intervention; Prognosis

$\mathbf{T}$ he SYNTAX (Synergy between PCI with Taxus and Cardiac Surgery) score (SS) ${ }^{1}$ was developed to comprehensively assess angiographic lesion severity, characterize procedural complexity, and is widely applied to direct treatment in difficult coronary disease cases, in particular 3-vessel disease ${ }^{2}$ and left main coronary artery disease. ${ }^{3,4}$ The model has also been proposed as a predictor of clinical outcome following percutaneous coronary intervention (PCI). ${ }^{5}$ In addition to the SS, a modified scoring system incorporating various clinical characteristics has been developed, termed the "clinical SYNTAX score (cSS) '. ${ }^{6}$ The predictability of both the SS and cSS has been validated in previous studies, ${ }^{7,8}$ but the SS was derived from a study that exclusively used paclitaxel-eluting stents, and its applicability to patients receiving 'limus'-eluting stents is unclear. Newly developed second-generation drugeluting stents (DES) have substantially reduced angiographic and clinical adverse events, ${ }^{9}$ but only a limited number of substudies ${ }^{10}$ have assessed the power of SS in predicting outcomes with second-generation DES. Further, no previous study has compared the predictability of both the SS and cSS exclusively for 'limus'-eluting stents.

In the present study, we examined the predictive value of the SS and cSS in predicting clinical outcome in patients receiving sirolimus-eluting (SES) or everolimus-eluting (EES) stent from

Received May 24, 2013; revised manuscript received July 1, 2013; accepted July 31, 2013; released online September 18, 2013 Time for primary review: 17 days

Department of Internal Medicine and Cardiovascular Center, Seoul National University Main Hospital, Seoul (K.W.P., J.K., S.-H.K., H.-S.A., H.-Y.L., H.-J.K., B.-K.K., B.-H.O., Y.-B.P., H.-S.K.); Seoul National University Bundang Hospital, Seongnam (I.-H.C., T.-J.Y.), Korea; and Piedmont Heart Institute, Atlanta, GA (D.E.K.), USA.

The first two authors contributed equally to this work (K.W.P., J.K.).

Mailing address: Hyo-Soo Kim, MD, PhD, Department of Internal Medicine and Cardiovascular Center, Seoul National University Hospital, 28 Yongon-dong Chongno-gu, Seoul 110-744, Korea. E-mail: hyosoo@snu.ac.kr and David Kandzari, MD, Piedmont Heart Institute, 275 Collier Road, Suite 300, Atlanta, GA 30309, USA. E-mail: david.kandzari@ piedmont.org

ISSN-1346-9843 doi:10.1253/circj.CJ-13-0645

All rights are reserved to the Japanese Circulation Society. For permissions, please e-mail: cj@j-circ.or.jp 
a multicenter registry that enrolled all-comer PCI cases with unrestricted use of the 2 types of stent.

\section{Methods}

An extended description of study methods is presented in Appendix S1.

\section{Study Design and Population \\ The Efficacy of Xience/Promus vs. Cypher in rEducing Late Loss after stenting (EXCELLENT) registry was a multicenter registry enrolling 5,159 patients from 29 centers in Korea be- tween April 2008 and May 2010 to compare the efficacy of EES (Xience/Promus) vs. SES (Cypher) in all comers undergoing PCI with unrestricted DES use. The study protocol was ap- proved by the ethics committee at each participating center, and was conducted according to the principles of the Declaration of Helsinki. All patients provided written, informed consent for participation in the registry.}

\section{Procedures and Follow-up}

PCI was performed using standard techniques. Clinical followup was performed at 1, 3,9 and 12 months after index PCI. All clinical events were reviewed by a clinical event committee whose members were unaware of the study purpose. Because the Korean health system is a government-run system with mandatory national health insurance, the vital status of $100 \%$ of the patients was cross-checked, even in those lost to follow-up. Patients lost on follow-up were considered at risk until the last contact date they were censored.

\section{Quantitative Coronary Angiography (QCA) and Calculation of SS}

Independent quantitative analysis of baseline coronary angiographic images and calculation of the SS were performed by 3 specialized QCA technicians at the Seoul National University Hospital Cardiovascular Clinical Research Center Angiographic Core Laboratory. For calculation of the cSS, the SS was multiplied with the value of the modified 'Age, Creatinine, and Left Ventricular Ejection Fraction (ACEF)' score, as described elsewhere. ${ }^{6}$

\section{Study Endpoints and Definitions}

The co-primary endpoints included the patient-oriented composite endpoint (POCE) and target-lesion failure (TLF). POCE was defined as a composite of all-cause death, any myocardial infarction (MI; including non-target vessel territory), and any repeat revascularization (including all target and non-target vessels, regardless of percutaneous or surgical method); TLF represented a composite of cardiac death, target-vessel MI, and target-lesion revascularization. Secondary endpoints were the individual components of the POCE, TLF, and definite/probable stent thrombosis as defined by the Academic Research Consortium. ${ }^{11}$

\section{Statistical Analyses}

All variables and outcome analysis were based on the SS tertiles. To estimate the independent effect of SS on clinical outcome, a multivariable Cox proportional hazards regression model using a backward elimination algorithm was used. Area under the curve (AUC) of receiver-operating characteristic (ROC) curves for SS and cSS was calculated. To minimize the selection bias between patients with different stents, propensity-score matching was done. A 2-sided $\mathrm{P}$ value less than 0.05 was considered statistically significant.

\section{Results}

Patients' Baseline Characteristics and Procedural Results A total of 5,159 patients were enrolled in the EXCELLENT registry. The angiographic images of 57 patients $(1.1 \%)$ were uninterpretable and excluded from the study. Therefore, baseline SS was calculated for 5,102 patients (98.9\%) consisting of 7,003 lesions (3,047 patients, 4,235 lesions in the EES group; 2,055 patients, 2,768 lesions in the SES group). Baseline clinical and angiographic characteristics are summarized in Table $\mathbf{S 1}$, and lesion characteristics are summarized in Table $\mathbf{S 2}$. This was an all-comer enriched PCI population with more than $60 \%$ of the patients presenting with acute coronary syndrome (ACS). Diabetes and hypertension was prevalent in $36.2 \%$ and $61.7 \%$ of the enrolled patients, respectively, with a slightly higher frequency in the EES group. Regarding lesion characteristics, $\mathrm{B} 2 / \mathrm{C}$ lesions were more common in the SES group $(64.1 \%$ vs. $67.1 \%, \mathrm{P}=0.016$ ), with a higher proportion of total occlusions (12.1\% vs. $16.1 \%, \mathrm{P}<0.001)$, long lesions ( $35.6 \%$ vs. $49.0 \%$, $\mathrm{P}<0.001)$, higher maximal deployment pressure $(13.46 \pm 4.79$ vs. $14.15 \pm 5.68 \mathrm{~atm}, \mathrm{P}<0.001)$, and longer total stent length (27.06 \pm 13.92 vs. $29.53 \pm 14.56 \mathrm{~mm}, \mathrm{P}<0.001)$. The proportion of lesions with severe calcification $(13.1 \%$ vs. $7.5 \%, \mathrm{P}<0.001)$ and severe proximal tortuosity was higher in the EES group (1.4\% vs. $0.6 \%, \mathrm{P}<0.001)$.

The mean baseline SS was 13.6 \pm 9.1 (range, 0-62.5). After stratification according to the type of inserted stent, the EES group had a modest but significantly higher SS than the SES group (13.9 \pm 9.6 vs. $13.2 \pm 8.3, \mathrm{P}=0.003)$. Patients were categorized into tertiles of the SS, which was defined as: low $\mathrm{SS}<8$ $(n=1,608$, interquartile range (IQR) 3.0-5.0, 971 patients with EES and 637 patients with SES); $8 \leq \mathrm{SS} \leq 16(\mathrm{n}=1,838$, IQR 9.0-12.0, 1,053 patients with EES and 785 patients with SES); high-SS >16 ( $n=1,656$, IQR 19.0-23.0, 1,023 patients with EES and 633 patients with SES). Baseline clinical characteristics and procedural characteristics stratified according to SS tertile are presented in Table 1, and Table 2 shows the lesion characteristics for patients in each SS tertile. Advanced age, diabetes mellitus (DM) and presentation with ACS, regional wall motion abnormality, left main vessel disease, and multivessel disease were all significantly more common in the high-SS tertile, in both the EES and SES cohort. Also, the number of treated vessels was higher, and ejection fraction (EF) was lower in the high$\mathrm{SS}$ tertile. Further, frequency of left main vessel as the target lesion, and prevalence of additional lesion complexity (eg, total occlusion, bifurcation) was higher in the high-SS group.

\section{Clinical Outcomes}

Overall, 5,010 patients (98.2\%) completed the 1 year follow-up. POCE occurred in $8.1 \%$ (412 patients) and TLF occurred in $2.8 \%$ (145 patients) during the 1-year follow-up. Clinical outcomes are shown in Table 3. From the whole population, both POCE ( $4.2 \%$ vs. $7.7 \%$ vs. $12.2 \%, \mathrm{P}<0.001)$ and TLF (1.6\% vs. $2.4 \%$ vs. $4.5 \%, \mathrm{P}<0.001)$ increased significantly with increasing $\mathrm{SS}$ tertile. For the secondary analysis endpoints, all of them occurred more frequently as the SS increased and all were statistically significant except for target-vessel MI. For revascularization in particular, the number of both clinically driven and non-clinically driven cases of revascularization increased with SS tertile. The cumulative survival curves for both POCE and TLF showed statistically significant differences among the low-, mid-, and high-SS groups (Figure 1). To evaluate if SS was an independent predictor for the endpoints, we used a Cox proportional hazard model that included covariates such as age, sex, body weight, diagnosis of ACS, comorbidities such as hy- 


\begin{tabular}{|c|c|c|c|c|}
\hline \multirow[b]{3}{*}{ Demographics } & \multicolumn{4}{|c|}{ EES } \\
\hline & Low SS (n=971) & Mid SS $(n=1,053)$ & High SS $(n=1,023)$ & $P$ value \\
\hline & & & & \\
\hline Age, years & $63 \pm 11$ & $64 \pm 11$ & $65 \pm 11$ & $<0.001$ \\
\hline Male, n (\%) & $661(68.1 \%)$ & $712(67.6 \%)$ & $674(65.9 \%)$ & 0.543 \\
\hline Weight, kg & $65.9 \pm 10.3$ & $65.4 \pm 11.3$ & $64.2 \pm 12.1$ & 0.002 \\
\hline Diabetes, n (\%) & $311(32.0 \%)$ & $387(36.8 \%)$ & $448(43.8 \%)$ & $<0.001$ \\
\hline Hypertension, n (\%) & $617(63.5 \%)$ & $667(63.3 \%)$ & $691(67.5 \%)$ & 0.138 \\
\hline Dyslipidemia, n (\%) & $330(34.0 \%)$ & $371(35.2 \%)$ & $381(37.2 \%)$ & 0.589 \\
\hline Smoking status* $\%$ & 29.6/21.0/47.7 & $28.4 / 17.7 / 52.0$ & $29.8 / 17.6 / 50.5$ & 0.355 \\
\hline Chronic renal failure, $\mathrm{n}(\%)$ & $24(2.5 \%)$ & $40(3.8 \%)$ & $41(4.0 \%)$ & 0.362 \\
\hline Dialysis, n (\%) & $17(1.8 \%)$ & $22(2.1 \%)$ & $26(2.5 \%)$ & 0.471 \\
\hline Previous PCI, n (\%) & $127(13.1 \%)$ & $171(16.2 \%)$ & $142(13.9 \%)$ & 0.203 \\
\hline Previous MI, n (\%) & $46(4.7 \%)$ & $67(6.4 \%)$ & $98(9.6 \%)$ & 0.001 \\
\hline Previous CVA, n (\%) & $66(6.8 \%)$ & $71(6.7 \%)$ & $112(10.9 \%)$ & 0.002 \\
\hline Congestive heart failure, $\mathrm{n}(\%)$ & $13(1.3 \%)$ & $25(2.4 \%)$ & $24(2.3 \%)$ & 0.191 \\
\hline Previous PVD, n (\%) & $9(0.9 \%)$ & $16(1.5 \%)$ & $22(2.2 \%)$ & 0.223 \\
\hline Previous COPD, n (\%) & $33(3.4 \%)$ & $44(4.2 \%)$ & $17(1.7 \%)$ & 0.003 \\
\hline Family history of CAD, $\mathrm{n}(\%)$ & $43(4.4 \%)$ & $61(5.8 \%)$ & $67(6.5 \%)$ & 0.092 \\
\hline Diagnosis, ${ }^{\dagger} \mathrm{n}(\%)$ & 2.9/38.6/42.3/8.4/7.8 & $3.6 / 37.3 / 36.4 / 10.9 / 11.8$ & 2.8/32.5/32.1/14.4/18.2 & $<0.001$ \\
\hline RWMA, n (\%) & $185(21.9 \%)$ & $283(30.9 \%)$ & $408(43.9 \%)$ & $<0.001$ \\
\hline Ejection fraction & $62.4 \pm 9.5$ & $59.9 \pm 10.6$ & $56.1 \pm 12.7$ & $<0.001$ \\
\hline Vessel disease, ${ }^{\ddagger} \%$ & 73.7/18.1/7.6 & $46.2 / 36.9 / 16.6$ & $21.6 / 34.7 / 43.5$ & $<0.001$ \\
\hline Left main vessel disease, $n(\%)$ & $5(0.5 \%)$ & $45(4.3 \%)$ & $123(12.0 \%)$ & $<0.001$ \\
\hline No. of treated lesions, $\%$ & $93.7 / 6.2 / 0.1$ & $74.3 / 24.3 / 1.4$ & $59.4 / 34.0 / 6.5$ & $<0.001$ \\
\hline \multicolumn{5}{|l|}{ Baseline biochemistry } \\
\hline Hemoglobin (g/dl) & $13.6 \pm 1.9$ & $13.4 \pm 2.0$ & $13.3 \pm 2.6$ & 0.006 \\
\hline Creatinine (mg/dl) & $1.09 \pm 1.00$ & $1.14 \pm 1.00$ & $1.19 \pm 1.26$ & 0.119 \\
\hline C-reactive protein (mg/dl) & $3.0 \pm 14.7$ & $4.4 \pm 29.3$ & $8.9 \pm 46.7$ & 0.002 \\
\hline Total cholesterol (mg/dl) & $174 \pm 43$ & $174 \pm 47$ & $175 \pm 43$ & 0.839 \\
\hline Triglyceride (mg/dl) & $141 \pm 88$ & $147 \pm 97$ & $141 \pm 91$ & 0.335 \\
\hline $\mathrm{HDL}(\mathrm{mg} / \mathrm{dl})$ & $44 \pm 12$ & $43 \pm 16$ & $42 \pm 11$ & 0.012 \\
\hline LDL (mg/dl) & $105 \pm 36$ & $105 \pm 38$ & $107 \pm 37$ & 0.265 \\
\hline \multicolumn{5}{|l|}{ Discharge medications } \\
\hline Aspirin, $\mathrm{n}(\%)$ & $944(97.2 \%)$ & $1,026(97.4 \%)$ & $990(96.8 \%)$ & 0.780 \\
\hline Clopidogrel, n (\%) & $951(97.9 \%)$ & $1,024(97.2 \%)$ & $990(96.8 \%)$ & 0.512 \\
\hline$\beta$-blocker, n (\%) & $533(54.9 \%)$ & $642(61.0 \%)$ & $672(65.7 \%)$ & $<0.001$ \\
\hline Statin, n (\%) & $831(85.6 \%)$ & $894(84.9 \%)$ & $880(86.0 \%)$ & 0.836 \\
\hline ACE inhibitor, $n(\%)$ & $319(32.9 \%)$ & $376(35.7 \%)$ & $412(40.3 \%)$ & 0.008 \\
\hline Angiotensin-receptor blocker, $\mathrm{n}(\%)$ & $325(33.5 \%)$ & $316(30.0 \%)$ & $296(28.9 \%)$ & 0.215 \\
\hline Calcium-channel blocker, $\mathrm{n}(\%)$ & $295(30.4 \%)$ & $302(28.7 \%)$ & $231(22.6 \%)$ & 0.001 \\
\hline
\end{tabular}

(Table 1 continued the next page.)

pertension, DM, dyslipidemia, chronic renal failure (CRF), previous MI, chronic obstructive pulmonary disease, cerebrovascular accident, and test results such as regional wall motion abnormality by echocardiography, and the hemoglobin and Creactive protein levels. Even after adjustment for various confounding factors, increasing SS was an independent predictor of clinical endpoints (Table 4).

\section{Comparison of Angiographic and CSS}

The clinical SS was calculated using the combination of the patient's age, left ventricular EF, and creatinine clearance calcu- lated by Cockcroft-Gault equation. There was a wide variation in the cSS, ranging from 0 to 400.73 , with a median of 15.91 . ROC curve analysis was performed to compare the predictability of outcome between SS and cSS. The predictability of SS and cSS was similar for POCE (AUC: 0.635 vs. 0.629 , for SS vs. cSS, $\mathrm{P}=0.599)$, but cSS was slightly superior to $\mathrm{SS}$ in predicting TLF (AUC: 0.625 vs. 0.680 , for SS vs. cSS, $\mathrm{P}=0.008$ ). The AUCs of other endpoints are shown in Table 5. The SS had better predictability for revascularization, whereas cSS was better in predicting death and cardiac death.

In subgroup analysis, the predictability of SS and cSS in pa- 
SES

\begin{tabular}{|c|c|c|c|c|}
\hline & Low SS (n=637) & Mid SS ( $n=785)$ & High SS (n=633) & $P$ value \\
\hline \multicolumn{5}{|l|}{ Demographics } \\
\hline Age, years & $61 \pm 11$ & $62 \pm 11$ & $64 \pm 11$ & $<0.001$ \\
\hline Male, n (\%) & $434(68.1 \%)$ & $538(68.6 \%)$ & $449(70.9 \%)$ & 0.495 \\
\hline Weight, kg & $65.8 \pm 10.7$ & $65.5 \pm 10.7$ & $65.1 \pm 11.8$ & 0.598 \\
\hline Diabetes, n (\%) & $182(28.6 \%)$ & $263(33.5 \%)$ & $254(40.1 \%)$ & 0.001 \\
\hline Hypertension, n (\%) & $335(52.6 \%)$ & $459(58.5 \%)$ & $380(60.0 \%)$ & 0.064 \\
\hline Dyslipidemia, n (\%) & $238(37.2 \%)$ & $269(34.3 \%)$ & $210(33.2 \%)$ & 0.174 \\
\hline Smoking status* $\%$ & $32.0 / 16.5 / 48.7$ & 29.6/18.7/49.3 & $32.2 / 16.4 / 49.6$ & 0.652 \\
\hline Chronic renal failure, n (\%) & $7(1.1 \%)$ & $30(3.8 \%)$ & $17(2.7 \%)$ & 0.014 \\
\hline Dialysis, n (\%) & $6(0.9 \%)$ & $19(2.4 \%)$ & $11(1.7 \%)$ & 0.107 \\
\hline Previous PCl, n (\%) & $111(17.4 \%)$ & $136(17.3 \%)$ & $103(16.3 \%)$ & 0.871 \\
\hline Previous MI, n (\%) & $61(9.6 \%)$ & $81(10.3 \%)$ & $69(10.9 \%)$ & 0.881 \\
\hline Previous CVA, n (\%) & $20(3.1 \%)$ & $47(6.0 \%)$ & $50(7.9 \%)$ & 0.001 \\
\hline Congestive heart failure, $\mathrm{n}(\%)$ & $6(0.9 \%)$ & $13(1.7 \%)$ & $12(1.9 \%)$ & 0.701 \\
\hline Previous PVD, n (\%) & $2(0.3 \%)$ & $16(2.0 \%)$ & $9(1.4 \%)$ & 0.053 \\
\hline Previous COPD, n (\%) & $9(1.4 \%)$ & $25(3.2 \%)$ & $19(3.0 \%)$ & 0.080 \\
\hline Family history of CAD, $\mathrm{n}(\%)$ & $31(4.9 \%)$ & $44(5.6 \%)$ & $26(4.1 \%)$ & 0.721 \\
\hline Diagnosis, ${ }^{\dagger} \mathrm{n}(\%)$ & $3.4 / 35.6 / 37.4 / 10.8 / 12.8$ & 2.7/34.3/34.3/11.8/16.9 & 2.1/29.9/30.7/11.2/26.2 & $<0.001$ \\
\hline RWMA, n (\%) & $168(31.8 \%)$ & 226 (35.4\%) & $266(51.5 \%)$ & $<0.001$ \\
\hline Ejection fraction & $61.7 \pm 10.3$ & $59.9 \pm 11.7$ & $55.9 \pm 13.1$ & $<0.001$ \\
\hline Vessel disease, $¥ \%$ & $68.6 / 24.5 / 6.4$ & $41.4 / 36.2 / 22.0$ & $25.4 / 34.8 / 39.7$ & $<0.001$ \\
\hline Left main vessel disease, $\mathrm{n}(\%)$ & $5(0.8 \%)$ & $32(4.1 \%)$ & $88(13.9 \%)$ & $<0.001$ \\
\hline No. of treated lesions, \% & $92.6 / 7.2 / 0.2$ & $75.3 / 22.8 / 1.9$ & $65.2 / 29.9 / 4.9$ & $<0.001$ \\
\hline \multicolumn{5}{|l|}{ Baseline biochemistry } \\
\hline Hemoglobin $(\mathrm{g} / \mathrm{dl})$ & $13.7 \pm 1.7$ & $13.7 \pm 2.1$ & $13.7 \pm 2.1$ & 0.938 \\
\hline Creatinine (mg/dl) & $1.02 \pm 0.80$ & $1.14 \pm 1.15$ & $1.16 \pm 1.15$ & 0.030 \\
\hline C-reactive protein $(\mathrm{mg} / \mathrm{dl})$ & $5.7 \pm 34.3$ & $6.4 \pm 36.4$ & $6.5 \pm 39.0$ & 0.935 \\
\hline Total cholesterol (mg/dl) & $175 \pm 43$ & $177 \pm 62$ & $181 \pm 47$ & 0.142 \\
\hline Triglyceride (mg/dl) & $144 \pm 102$ & $144 \pm 95$ & $149 \pm 104$ & 0.637 \\
\hline $\mathrm{HDL}(\mathrm{mg} / \mathrm{dl})$ & $44 \pm 11$ & $43 \pm 11$ & $43 \pm 12$ & 0.100 \\
\hline LDL (mg/dl) & $106 \pm 37$ & $108 \pm 60$ & $112 \pm 40$ & 0.062 \\
\hline \multicolumn{5}{|l|}{ Discharge medications } \\
\hline Aspirin, $\mathrm{n}(\%)$ & $631(99.1 \%)$ & $776(98.9 \%)$ & $617(97.5 \%)$ & 0.096 \\
\hline Clopidogrel, n (\%) & $618(97.0 \%)$ & $768(97.8 \%)$ & $610(96.4 \%)$ & 0.154 \\
\hline$\beta$-blocker, $\mathrm{n}(\%)$ & $401(63.0 \%)$ & $511(65.1 \%)$ & $420(66.4 \%)$ & 0.556 \\
\hline Statin, n (\%) & $509(79.8 \%)$ & $643(81.9 \%)$ & $518(81.8 \%)$ & 0.350 \\
\hline ACE inhibitor, $n(\%)$ & $253(39.7 \%)$ & $315(40.1 \%)$ & $269(42.5 \%)$ & 0.147 \\
\hline Angiotensin-receptor blocker, n (\%) & 207 (32.5\%) & $256(32.6 \%)$ & $194(30.6 \%)$ & 0.874 \\
\hline Calcium-channel blocker, n (\%) & $204(32.0 \%)$ & $236(30.1 \%)$ & $156(24.6 \%)$ & 0.040 \\
\hline
\end{tabular}

Data are presented as the mean value \pm SD or percentage of patients. ${ }^{*}$ Smoking status: current smoker/ex-smoker/never smoked. ${ }^{t}$ Diagnosis: silent ischemia/chronic stable angina/unstable angina/NSTEMI/STEMI. $¥$ Vessel disease: 1VD/2VD/3VD.

$\mathrm{ACE}$, angiotensin-converting enzyme; CAD, coronary artery disease; COPD, Chronic obstructive pulmonary disease; CVA, cerebrovascular accident; EES, everolimus-eluting stent; HDL, high-density lipoprotein; LDL, low-density lipoprotein; MI, myocardial infarction; PCI, percutaneous coronary intervention; PVD, peripheral vascular disease; RWMA, regional wall motion abnormality; SES, sirolimus-eluting stent; SS, SYNTAX score; VD, vessel disease.

tients with risk factors such as old age, DM, CRF and decreased left ventricular function were analyzed. Compared with the SS, the cSS had better predictability in these particular patients, whereas SS tended to be superior in patients without risk factors (Table S3).

\section{Subgroup Analysis According to Stent Type}

As the SES is a first-generation DES that is no longer commercially available, and the EES is a second-generation DES developed with the aim of improving clinical outcomes compared with the first-generation DES and is widely used in current ev- eryday practice, we compared the endpoints according to the type of implanted stent. Increasing SS was associated with higher event rates for both stent types (POCE: $3.4 \%$ vs. $6.7 \%$ vs. $11.4 \%, \mathrm{P}<0.001$ in the EES group and $5.5 \%$ vs. $9.1 \%$ vs. $13.4 \%$, $\mathrm{P}<0.001$ in the SES group and TLF: $0.9 \%$ vs. $2.6 \%$ vs. $4.2 \%$, $\mathrm{P}<0.001$ in the EES group and $2.5 \%$ vs. $2.3 \%$ vs. $5.1 \%, \mathrm{P}=0.007$ in the SES group; Table S4), which was corroborated by Kaplan Meier cumulative survival curves (Figure 2).

In our comparison of the stents, POCE was lower in the EES group $(7.3 \%$ vs. $9.3 \%$, hazard ratio (HR) $1.310,95 \%$ confidence interval $1.070-1.604, \mathrm{P}=0.010$ ), mainly because of the lower 


\begin{tabular}{|c|c|c|c|c|}
\hline & \multicolumn{4}{|c|}{ EES } \\
\hline & Low SS & Mid SS & High SS & $P$ value \\
\hline \multicolumn{5}{|l|}{ Target-vessel location } \\
\hline Left main, $n(\%)$ & $6 / 1,065(0.6 \%)$ & $49 / 1,441(3.4 \%)$ & $128 / 1,729(7.4 \%)$ & $<0.001$ \\
\hline Left anterior descending artery, $\mathrm{n}(\%)$ & $449 / 1,065(42.2 \%)$ & $700 / 1,441(48.6 \%)$ & $747 / 1,729(43.2 \%)$ & 0.001 \\
\hline Left circumflex coronary artery, $\mathrm{n}(\%)$ & $279 / 1,065$ (26.2\%) & $296 / 1,441$ (20.5\%) & $398 / 1,729(23.0 \%)$ & 0.004 \\
\hline Right coronary artery, n (\%) & $331 / 1,065$ (31.1\%) & $396 / 1,441(27.5 \%)$ & $452 / 1,729(26.1 \%)$ & 0.017 \\
\hline Bypass graft, n (\%) & $0 / 1,065(0 \%)$ & $0 / 1,441(0 \%)$ & $4 / 1,729(0.2 \%)$ & 0.055 \\
\hline \multicolumn{5}{|l|}{ ACC/AHA lesion class } \\
\hline $\mathrm{A}, \mathrm{n}(\%)$ & $72 / 948(7.6 \%)$ & $87 / 1,258(6.9 \%)$ & $88 / 1,438(6.1 \%)$ & 0.363 \\
\hline $\mathrm{B} 1, \mathrm{n}(\%)$ & $360 / 948(38.0 \%)$ & $406 / 1,258(32.3 \%)$ & $297 / 1,438(20.7 \%)$ & $<0.001$ \\
\hline B2, n (\%) & $278 / 948(29.3 \%)$ & $344 / 1,258(27.3 \%)$ & $363 / 1,438(25.2 \%)$ & 0.085 \\
\hline $\mathrm{C}, \mathrm{n}(\%)$ & $238 / 948(25.1 \%)$ & $421 / 1,258(33.5 \%)$ & $690 / 1,438(48.0 \%)$ & $<0.001$ \\
\hline $\mathrm{B} 2 / \mathrm{C}, \mathrm{n}(\%)$ & $516 / 948(54.4 \%)$ & $765 / 1,258(60.8 \%)$ & $1,053 / 1,438(73.2 \%)$ & $<0.001$ \\
\hline Severe calcification, $\mathrm{n}(\%)$ & $77 / 771(10.0 \%)$ & 105/995 (10.6\%) & $202 / 1,174(17.2 \%)$ & $<0.001$ \\
\hline Thrombus, n (\%) & $75 / 951(7.9 \%)$ & $89 / 1,195(6.9 \%)$ & $169 / 1,354(11.1 \%)$ & $<0.001$ \\
\hline Bifurcated lesion, n (\%) & $55 / 1,057(5.2 \%)$ & $156 / 1,430(10.9 \%)$ & 208/1,713 (12.1\%) & $<0.001$ \\
\hline Severe proximal tortuosity, n (\%) & $17 / 981(1.6 \%)$ & $18 / 1,312(1.3 \%)$ & $23 / 1,548(1.4 \%)$ & 0.978 \\
\hline Total occlusion, $\mathrm{n}(\%)$ & $3 / 1,060(0.3 \%)$ & $18 / 1,423(1.3 \%)$ & $71 / 1,676(4.2 \%)$ & $<0.001$ \\
\hline Aneurysm, n (\%) & $2 / 1,064(0.2 \%)$ & $5 / 1,430(0.3 \%)$ & $9 / 1,683(0.5 \%)$ & 0.347 \\
\hline Ulceration, n (\%) & $3 / 1,064(0.3 \%)$ & $13 / 1,430(0.9 \%)$ & $13 / 1,683(0.8 \%)$ & 0.155 \\
\hline Ostial lesion, n (\%) & $44 / 1,064(4.1 \%)$ & $163 / 1,430(11.4 \%)$ & $282 / 1,683(16.8 \%)$ & $<0.001$ \\
\hline TIMI flow* $(\%)$ & $3.5 / 4.2 / 5.9 / 86.4$ & 8.2/3.7/6.3/81.9 & $16.3 / 5.1 / 5.9 / 72.7$ & $<0.001$ \\
\hline Lesion length ${ }^{10}$ & $14.7 \pm 8.2$ & $17.1 \pm 10.6$ & $21.6 \pm 14.0$ & $<0.001$ \\
\hline Small vessel $(<2.75 \mathrm{~mm}), \mathrm{n}(\%)$ & 132/1,062 (12.4\%) & $200 / 1,431(14.0 \%)$ & $367 / 1,714(21.4 \%)$ & $<0.001$ \\
\hline Long lesion (>27 mm), n (\%) & $257 / 1,062(24.2 \%)$ & $462 / 1,431(32.3 \%)$ & $779 / 1,715(45.4 \%)$ & $<0.001$ \\
\hline Max. pressure deployment, atm & $13.1 \pm 4.5$ & $13.6 \pm 5.1$ & $13.6 \pm 4.7$ & 0.012 \\
\hline Total stent length ${ }^{10}$ & $22.9 \pm 8.5$ & $25.8 \pm 12.0$ & $30.6 \pm 16.9$ & $<0.001$ \\
\hline No. of stents ${ }^{10}$ & $1.08 \pm 0.31$ & $1.16 \pm 0.42$ & $1.29 \pm 0.57$ & $<0.001$ \\
\hline Device success, $n(\%)$ & $1,049 / 1,057$ (99.2\%) & $1,411 / 1,432(98.5 \%)$ & $1,674 / 1,719(97.4 \%)$ & 0.001 \\
\hline Lesion success, $\mathrm{n}(\%)$ & $1,051 / 1,059(99.2 \%)$ & $1,410 / 1,432(98.5 \%)$ & $1,671 / 1,720(97.2 \%)$ & $<0.001$ \\
\hline Procedural success, $n(\%)$ & $1,049 / 1,057(99.2 \%)$ & $1,408 / 1,430(98.5 \%)$ & $1,670 / 1,720(97.1 \%)$ & $<0.001$ \\
\hline
\end{tabular}

(Table 2 continued the next page.)

level of revascularization $(5.2 \%$ vs. $7.4 \%, \mathrm{P}=0.001)$, but there was no difference in TLF between the 2 groups ( $2.6 \%$ vs. $3.2 \%$, $\mathrm{P}=0.198)$. Otherwise, no other significant differences in secondary outcomes according to stent type were observed (Table S5). Because of the significant differences between the 2 stent groups in baseline clinical characteristics and angiographic characteristics (Tables S1, S2), the populations was divided by SS tertile to match the angiographic characteristics and 1:1 propensityscore matching was done for the baseline clinical characteristics in each tertile, yielding 882 pairs $(265,330$, and 287 pairs in $\mathrm{SS}<8,8 \leq \mathrm{SS} \leq 16, \mathrm{SS}>16$ groups, respectively). The baseline clinical characteristics of the matched groups showed a balanced distribution (Tables S6-8). The rate of POCE and TLF was analyzed in each matched subgroup and there was no significant difference of POCE and TLF by allocated stent in any of the 3 SS tertiles (Table S9, Figure S1).

\section{Discussion}

The present study investigated the ability of the SS and cSS to predict clinical outcome after unrestricted use of "limus-eluting" stents from a large-scale registry that included an enriched PCI population more reflective of current day practice. We found that as the tertile of the SS increased, both POCE and TLF in- creased, and that the SS was an independent predictor of POCE and TLF even after multivariable adjustment for possible confounding factors. Second, the predictability of SS and cSS was similar for POCE, but cSS was slightly superior to SS in predicting TLF. Third, when stratified according to stent type, the positive relationship between SS tertiles and event rates was similar for both EES and SES. Fourth, in a propensity-score matched analysis, there was no significant difference in POCE and TLF by stent type in all 3 SS tertiles.

To the best of our knowledge, this is the largest study evaluating the predictability of SS and cSS on outcome for "limus"eluting stents. After the SS was developed from a paclitaxeleluting first-generation DES, the validity of the SS was confirmed in retrospective studies, ${ }^{3,12}$ and especially in complex coronary lesions. ${ }^{13}$ However, most of the analyses were based on firstgeneration stents, except for 2 studies that validated the SS in second-generation "limus-eluting" stents. The first study was the RESOLUTE All-Comers trial that evaluated the SS in 2,033 patients treated with either EES or zotarolimus-eluting Resolute stents. ${ }^{14}$ The second study was the LEADERS trial, which that examined the usefulness of the SS in 1,707 patients receiving either biolimus-eluting stents or SES..$^{10}$ In both studies, the SS was significantly associated with increased rates of clinical events after PCI. Compared with previous studies, this present 


\begin{tabular}{|c|c|c|c|c|}
\hline & \multicolumn{4}{|c|}{ SES } \\
\hline & Low SS & Mid SS & High SS & $P$ value \\
\hline \multicolumn{5}{|l|}{ Target-vessel location } \\
\hline Left main, $n(\%)$ & $5 / 713(0.7 \%)$ & $37 / 1,076(3.4 \%)$ & 95/977 (9.7\%) & $<0.001$ \\
\hline Left anterior descending artery, $\mathrm{n}(\%)$ & $347 / 713(48.7 \%)$ & $549 / 1,076(50.9 \%)$ & $508 / 977(52.1 \%)$ & 0.364 \\
\hline Left circumflex coronary artery, $\mathrm{n}(\%)$ & $176 / 713(24.7 \%)$ & $224 / 1,076(20.8 \%)$ & $187 / 977(19.2 \%)$ & 0.022 \\
\hline Right coronary artery, $\mathrm{n}(\%)$ & $185 / 713(25.9 \%)$ & $268 / 1,076(24.9 \%)$ & 226/977 (23.2\%) & 0.407 \\
\hline Bypass graft, n (\%) & $0 / 713(0 \%)$ & $0 / 1,076(0 \%)$ & $0 / 977(0 \%)$ & NA \\
\hline \multicolumn{5}{|l|}{ ACC/AHA lesion class } \\
\hline $\mathrm{A}, \mathrm{n}(\%)$ & $31 / 622(5.0 \%)$ & $44 / 880(5.0 \%)$ & $23 / 764(3.0 \%)$ & 0.090 \\
\hline $\mathrm{B} 1, \mathrm{n}(\%)$ & $220 / 622$ (35.4\%) & $262 / 880(29.7 \%)$ & $165 / 764(21.7 \%)$ & $<0.001$ \\
\hline $\mathrm{B} 2, \mathrm{n}(\%)$ & $138 / 622(22.2 \%)$ & $177 / 880(20.1 \%)$ & $176 / 764(23.1 \%)$ & 0.309 \\
\hline $\mathrm{C}, \mathrm{n}(\%)$ & $233 / 622(37.5 \%)$ & $399 / 880(45.2 \%)$ & $398 / 764(52.2 \%)$ & $<0.001$ \\
\hline $\mathrm{B} 2 / \mathrm{C}, \mathrm{n}(\%)$ & $371 / 622(59.6 \%)$ & $576 / 880(65.3 \%)$ & $574 / 764(75.3 \%)$ & $<0.001$ \\
\hline Severe calcification, $n(\%)$ & $21 / 494(4.3 \%)$ & $50 / 672(7.4 \%)$ & $60 / 590(10.2 \%)$ & 0.001 \\
\hline Thrombus, n (\%) & $36 / 627(5.7 \%)$ & $78 / 894(8.7 \%)$ & $80 / 739(9.8 \%)$ & 0.018 \\
\hline Bifurcated lesion, $\mathrm{n}(\%)$ & $51 / 701(7.3 \%)$ & $109 / 1,060(10.3 \%)$ & $150 / 967(15.5 \%)$ & $<0.001$ \\
\hline Severe proximal tortuosity, $\mathrm{n}(\%)$ & $4 / 700(0.6 \%)$ & $7 / 1,053(0.7 \%)$ & $6 / 964(0.6 \%)$ & 0.029 \\
\hline Total occlusion, $\mathrm{n}(\%)$ & $3 / 700(0.4 \%)$ & $14 / 1,053(1.3 \%)$ & $36 / 964(3.7 \%)$ & $<0.001$ \\
\hline Aneurysm, $\mathrm{n}(\%)$ & $1 / 708(0.1 \%)$ & $3 / 1,060(0.3 \%)$ & $5 / 972(0.5 \%)$ & 0.396 \\
\hline Ulceration, $\mathrm{n}(\%)$ & $5 / 708(0.7 \%)$ & $8 / 1,060(0.8 \%)$ & 12/972 (1.2\%) & 0.419 \\
\hline Ostial lesion, $\mathrm{n}(\%)$ & $43 / 708(6.1 \%)$ & $138 / 1,060(13.0 \%)$ & $172 / 972(17.7 \%)$ & $<0.001$ \\
\hline TIMI flow* $(\%)$ & 3.7/4.6/6.3/85.3 & $9.4 / 6.9 / 6.5 / 77.2$ & $21.7 / 7.4 / 4.6 / 66.3$ & $<0.001$ \\
\hline Lesion length ${ }^{10}$ & $16.2 \pm 9.1$ & $19.4 \pm 11.7$ & $22.8 \pm 13.8$ & $<0.001$ \\
\hline Small vessel $(<2.75 \mathrm{~mm}), \mathrm{n}(\%)$ & $104 / 711(14.6 \%)$ & $166 / 899(15.6 \%)$ & $218 / 753(22.5 \%)$ & $<0.001$ \\
\hline Long lesion (>27 mm), n (\%) & $279 / 711(39.2 \%)$ & $508 / 1,065(47.7 \%)$ & $559 / 971(57.6 \%)$ & $<0.001$ \\
\hline Max. pressure deployment, atm & $13.5 \pm 4.7$ & $13.9 \pm 4.9$ & $14.8 \pm 6.9$ & $<0.001$ \\
\hline Total stent length ${ }^{10}$ & $24.8 \pm 89$ & $28.8 \pm 14.2$ & $33.8 \pm 16.9$ & $<0.001$ \\
\hline No. of stents ${ }^{10}$ & $1.05 \pm 0.23$ & $1.17 \pm 0.46$ & $1.32 \pm 0.59$ & $<0.001$ \\
\hline Device success, $\mathrm{n}(\%)$ & 695/703 (98.9\%) & $1,056 / 1,064(99.2 \%)$ & 959/971 (98.8\%) & 0.522 \\
\hline Lesion success, $\mathrm{n}(\%)$ & $693 / 702(98.7 \%)$ & $1,051 / 1,066(98.6 \%)$ & $950 / 974(97.5 \%)$ & 0.105 \\
\hline Procedural success, $\mathrm{n}(\%)$ & $693 / 703(98.6 \%)$ & $1,053 / 1,604(99.0 \%)$ & 958/973 (98.5\%) & 0.578 \\
\hline
\end{tabular}

Data are presented as the mean value \pm SD or percentage of patients. ${ }^{*}$ TIMI (Thrombolysis In Myocardial Infarction) flow grade: 0/1/2/3. Abbreviations as in Table 1.

analysis included a larger population and we showed that the SS is also valid for another second-generation DES, the EES, which is one of the most widely used DES in current day practice. Moreover, by propensity-score matching, we could measure the outcome of SES and EES in each SS tertile.

The present registry was an all-comer study without any exclusion criteria other than patient refusal to participate. Therefore, many high-risk patients were included in this registry. More than $60 \%$ of the study population presented with ACS, more than one-third of the patients had DM, and over two-thirds of the lesions were type B2/C. There was a high prevalence of chronic total occlusions, left main lesions, highly calcified lesions, and multivessel revascularizations, suggesting that the population analyzed was an enriched PCI population well reflective of current day practice with DES. Another strong point of the study was that clinical follow-up was meticulously performed with independent core laboratory and study adjudication, and with a high level of completeness of follow-up. In particular, the follow-up loss rate was less than $2 \%$, and the survival status of $100 \%$ of the patients was confirmed with a national registry.

One observation from the present study was the suggestion of a temporal trend toward more patients undergoing complex percutaneous revascularization procedures. The SES group, which was a historical control and had PCI performed in an earlier time period than the EES group, had a significantly lower SS compared with the EES group (13.9 \pm 9.6 vs. 13.2 \pm 8.3 , $\mathrm{P}=0.003$ in the EES and SES groups, respectively). This may be a consequence of the advances in the technology of PCI, with improved device deliverability, demonstration of improved outcomes with advanced generation DES, and evolution of PCI skills of the operators.

In the present study, we compared the predictability of SS and cSS for clinical outcomes after PCI. One of the most significant limitations of the SS is the omission of clinical variables from its calculation. ${ }^{15,16}$ Therefore, alternative scoring systems have been proposed, including the cSS, which is a product of the SS and the ACEF score,${ }^{17}$ and has been shown to improve the predictive ability for adverse clinical outcomes in previous studies albeit with fewer patients. ${ }^{6,7}$ In our study, by combining clinical variables with the anatomical SS, we identified a significant change in predictability of some factors. In particular, the predictability of the scoring system improved significantly in forecasting hard clinical safety outcomes such as all-cause death and cardiac death, whereas the predictability decreased in efficacy outcomes, such as revascularization. That is to say, the SS predicted restenosis-based outcomes quite well, with incremental benefit of adding the clinical components to identify other components of patient risk. This suggests that 


\begin{tabular}{|c|c|c|c|c|}
\hline & Low SS $(n=1,608)$ & Mid SS $(n=1,838)$ & High SS $(n=1,656)$ & $P$ value \\
\hline POCE* & $68(4.2 \%)$ & $142(7.7 \%)$ & $202(12.2 \%)$ & $<0.001$ \\
\hline Death & $11(0.7 \%)$ & $34(1.8 \%)$ & $48(2.9 \%)$ & $<0.001$ \\
\hline Myocardial infarction & $2(0.1 \%)$ & $9(0.5 \%)$ & $12(0.7 \%)$ & 0.036 \\
\hline Revascularization & $55(3.4 \%)$ & $107(5.8 \%)$ & $150(9.1 \%)$ & $<0.001$ \\
\hline Clinically driven & $43(2.7 \%)$ & $82(4.5 \%)$ & $116(7.0 \%)$ & $<0.001$ \\
\hline Non-clinically driven & $12(0.7 \%)$ & $25(1.4 \%)$ & $34(2.1 \%)$ & 0.006 \\
\hline TLF $^{\dagger}$ & $25(1.6 \%)$ & $45(2.4 \%)$ & $75(4.5 \%)$ & $<0.001$ \\
\hline Cardiac death & $10(0.6 \%)$ & $21(1.1 \%)$ & $29(1.8 \%)$ & 0.011 \\
\hline $\begin{array}{l}\text { Target-vessel myocardial } \\
\text { infarction }\end{array}$ & $2(0.1 \%)$ & $8(0.4 \%)$ & $9(0.5 \%)$ & 0.124 \\
\hline Target-lesion revascularization & $13(0.8 \%)$ & $20(1.1 \%)$ & $43(2.6 \%)$ & $<0.001$ \\
\hline $\begin{array}{l}\text { ARC definite/probable stent } \\
\text { thrombosis }{ }^{\ddagger}\end{array}$ & $3(0.2 \%)$ & $7(0.4 \%)$ & $22(1.3 \%)$ & $<0.001$ \\
\hline
\end{tabular}

Values are $\mathrm{n}(\%) .{ }^{*}$ Patient-oriented composite endpoint defined as a composite of all-cause mortality, any myocardial infarction, and any revascularization at 1-year follow-up. †Target-lesion failure: cardiac death, target-vessel myocardial infarction and clinically indicated target-lesion revascularization at 1-year follow-up. ‡Defined according to the Academic Research Consortium (ARC).

Abbreviation as in Table 1.
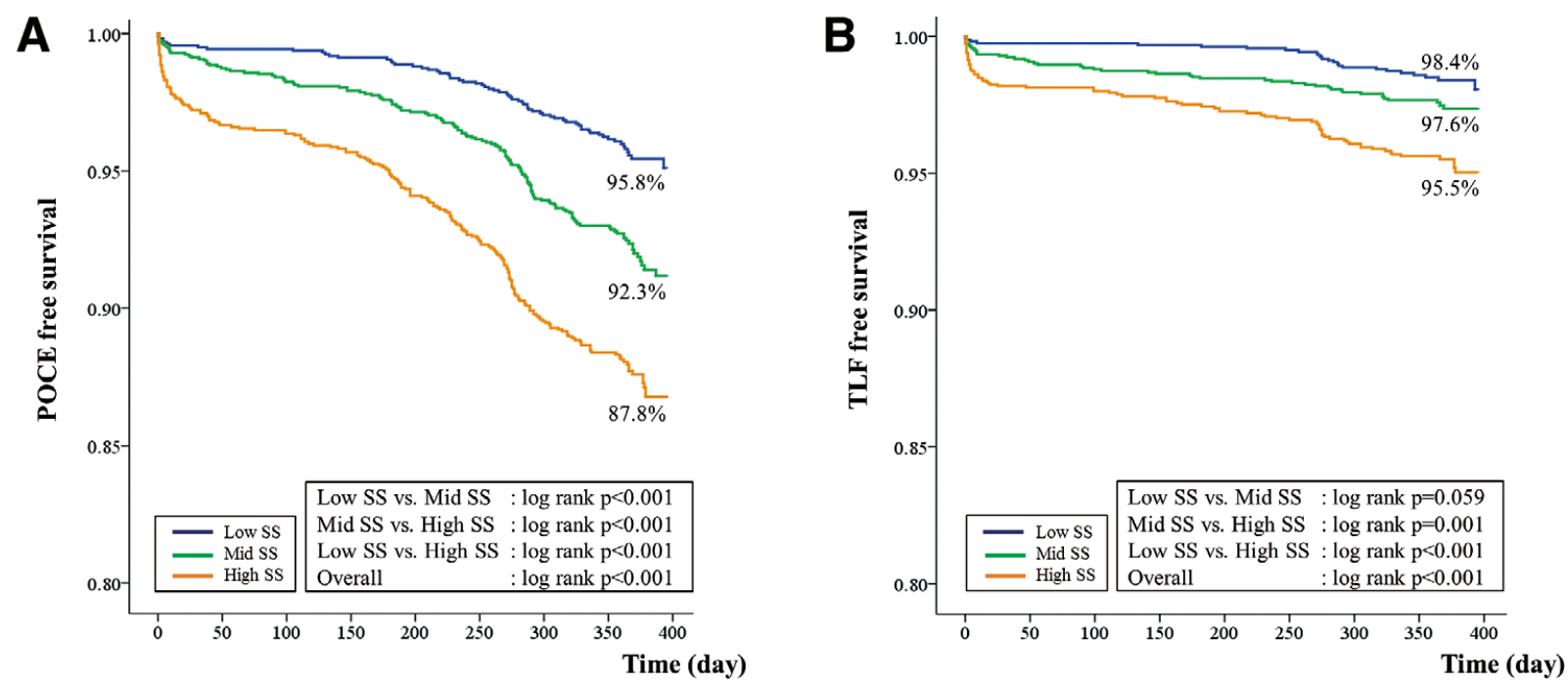

\begin{tabular}{lllll}
\hline No at risk & & & & \\
\hline Low SS & 1608 & 1581 & 1571 & 1523 \\
Mid SS & 1838 & 1783 & 1761 & 1679 \\
High SS & 1656 & 1572 & 1534 & 1444 \\
\hline
\end{tabular}

\begin{tabular}{lllll}
\hline No at risk & & & & \\
\hline Low SS & 1608 & 1585 & 1583 & 1550 \\
Mid SS & 1838 & 1788 & 1777 & 1739 \\
High SS & 1656 & 1588 & 1571 & 1532 \\
\hline
\end{tabular}

Figure 1. Kaplan-Meier survival curves of (A) patient-oriented composite endpoint (POCE) and (B) target-lesion failure (TLF). The cumulative survival curves for both POCE and TLF showed statistically significant differences between low-SS (0-8), mid-SS (8-16), and high-SS (>16) groups. SS, SYNTAX score.

clinical factors added to the angiographic factors may result in a better system of event scoring.

When divided into tertiles of the SS, the event rate increased with higher SS tertile and was statistically significant regarding every endpoint except target-vessel MI, which showed a statistically non-significant numerical increase with higher SS. Also, the SS tertile was an independent predictor for primary endpoints, showing the highest HR for POCE compared with the other factors. This was a finding consistent with the RESOLUTE all-comer trial and LEADRERS trial, but both those studies had limited factors incorporated into the Cox proportional hazards regression model. In the present study, the SS remained as a strong predictor even after compensating for various traditional risk factors. Finally, rates of stent thrombosis increased with higher SS tertile. Several reasons may explain why high lesion complexity may result in higher rates of stent thrombosis. First, heavily calcified lesions may cause underexpansion of the stents. Another may be that PCI of complex coronary lesions with difficult anatomy results in more vessel injury. Finally, severe complex lesions are usually treated using more metal (long stent- 


\begin{tabular}{|c|c|c|c|c|}
\hline \multirow[b]{2}{*}{ POCE* } & \multicolumn{2}{|c|}{ Factor } & HR (95\% Cl) & \multirow{2}{*}{$\begin{array}{l}\text { P value } \\
<0.001\end{array}$} \\
\hline & SYNTAX score & Low SS vs. mid SS & $2.216(1.474-3.332)$ & \\
\hline & & Low SS vs. high SS & $3.221(2.175-4.769)$ & $<0.001$ \\
\hline & & Mid SS vs. high SS & $1.453(1.095-1.927)$ & 0.010 \\
\hline & & \multicolumn{2}{|c|}{$P$ value of trend $d^{\ddagger}$} & $<0.001$ \\
\hline & \multicolumn{2}{|c|}{ Sex (male vs. female) } & $1.328(0.983-1.794)$ & 0.064 \\
\hline & \multicolumn{2}{|c|}{ Diagnosis of ACS } & $1.328(1.001-1.761)$ & 0.049 \\
\hline & \multicolumn{2}{|c|}{ Hypertension } & $1.332(1.003-1.763)$ & 0.047 \\
\hline & \multicolumn{2}{|c|}{ Hemoglobin } & $1.139(1.063-1.221)$ & $<0.001$ \\
\hline & \multicolumn{2}{|c|}{ COPD } & $2.008(1.185-3.401)$ & 0.010 \\
\hline \multirow[t]{10}{*}{$\mathrm{TLF}^{\dagger}$} & \multirow[t]{4}{*}{ SYNTAX score } & Low SS vs. mid SS & $1.647(0.851-3.118)$ & 0.139 \\
\hline & & Low SS vs. high SS & $2.241(1.187-4.232)$ & 0.013 \\
\hline & & Mid SS vs. high SS & $1.361(0.833-2.222)$ & 0.218 \\
\hline & & \multicolumn{2}{|c|}{$P$ value of trend $d^{\ddagger}$} & 0.041 \\
\hline & \multicolumn{2}{|c|}{ Chronic renal failure } & $3.937(2.045-7.576)$ & $<0.001$ \\
\hline & \multicolumn{2}{|c|}{ Sex (male vs. female) } & $1.564(0.918-2.663)$ & 0.100 \\
\hline & \multicolumn{2}{|c|}{ Previous CVA } & $1.927(1.074-3.456)$ & 0.028 \\
\hline & \multicolumn{2}{|c|}{ Diabetes mellitus } & $1.855(1.171-2.941)$ & 0.008 \\
\hline & \multicolumn{2}{|c|}{ Body weight (per kg) } & $1.030(1.006-1.054)$ & 0.014 \\
\hline & \multicolumn{2}{|c|}{ COPD } & $3.509(1.745-7.042)$ & $<0.001$ \\
\hline
\end{tabular}

*Patient-oriented composite endpoint: defined as a composite of all-cause mortality, any myocardial infarction, and any revascularization at 1-year follow-up. Covariates such as age, sex, diagnosis of ACS, comorbidities such as diabetes mellitus, dyslipidemia, chronic renal failure, previous $\mathrm{MI}$, CVA and test results such as regional wall motion abnormality by echocardiography and C-reactive protein levels were eliminated according to the backward elimination algorithm. †Target-lesion failure: cardiac death, target-vessel myocardial infarction and clinically indicated target-lesion revascularization at 1-year follow-up. Covariates such as age, diagnosis of ACS, comorbidities such as hypertension, dyslipidemia, previous $\mathrm{MI}$, and test results such as regional wall motion abnormality by echocardiography, hemoglobin and C-reactive protein levels were eliminated according to the backward elimination algorithm. ${ }^{\text {TTrend }}$ estimated by linearby-linear association.

ACS, acute coronary syndrome; $\mathrm{Cl}$, confidence interval; HR, hazard ratio. Other abbreviations as in Table 1.

Table 5. AUC of a Receiver-Operating Characteristic for Clinical Outcome by SS and CSS

\begin{tabular}{|c|c|c|c|}
\hline & AUC $(95 \% \mathrm{Cl})$ for SS & AUC $(95 \% \mathrm{Cl})$ for cSS & $P$ value \\
\hline POCE* $^{*}$ & $0.635(0.605-0.666)$ & $0.629(0.599-0.660)$ & 0.599 \\
\hline Death & $0.654(0.588-0.720)$ & $0.795(0.739-0.851)$ & $<0.001$ \\
\hline Myocardial Infarction & $0.627(0.523-0.732)$ & $0.673(0.548-0.799)$ & 0.275 \\
\hline Revascularization & $0.624(0.590-0.658)$ & $0.577(0.543-0.611)$ & $<0.001$ \\
\hline TLF $^{\dagger}$ & $0.625(0.570-0.680)$ & $0.680(0.627-0.733)$ & 0.008 \\
\hline Cardiac death & $0.631(0.546-0.715)$ & $0.782(0.709-0.855)$ & $<0.001$ \\
\hline Target-vessel MI & $0.578(0.461-0.695)$ & $0.602(0.462-0.742)$ & 0.627 \\
\hline Target-lesion revascularization & $0.623(0.545-0.701)$ & $0.599(0.524-0.674)$ & 0.390 \\
\hline ARC definite/probable stent thrombosis ${ }^{\ddagger}$ & $0.647(0.521-0.773)$ & $0.652(0.529-0.774)$ & 0.824 \\
\hline \multicolumn{4}{|l|}{ Long-term outcome ${ }^{\star *}$} \\
\hline POCE $^{*}$ & $0.621(0.588-0.654)$ & $0.603(0.570-0.637)$ & 0.143 \\
\hline $\mathrm{TLF}^{\dagger}$ & $0.604(0.536-0.673)$ & $0.647(0.581-0.714)$ & 0.117 \\
\hline
\end{tabular}

${ }^{*}$ Patient-oriented composite endpoint: defined as a composite of all-cause mortality, any myocardial infarction, and any revascularization at 1-year follow-up. †Target-lesion failure: cardiac death, target-vessel myocardial infarction and clinically indicated target-lesion revascularization at 1-year follow-up. ‡Defined according to the Academic Research Consortium (ARC). ${ }^{\star *}$ Defined as outcomes between 30 days and 1 year, post-PCl.

AUC, area under the curve; cSS, clinical SYNTAX score. Other abbreviations as in Tables 1,4.

ing is more prevalent). These are all known risk factors for stent thrombosis. ${ }^{18}$

In our comparison between stents, the whole population was divided into $3 \mathrm{SS}$ tertiles to match the angiographic findings and a propensity score was calculated to match the clinical findings. Although there was a higher rate of POCE in the EES group from the crude population, after the matched analysis, the EESand SES-inserted groups had no difference in patient-oriented outcomes (ie, POCE) or stent-oriented outcomes (ie, TLF). This was a finding consistent with previous results. ${ }^{19}$ The poor outcome in the SES group from the crude population may be explained by the more complex coronary lesions in the SES group (ie, higher proportion of B2/C lesions, total occluded lesions and long lesions). 
A

a

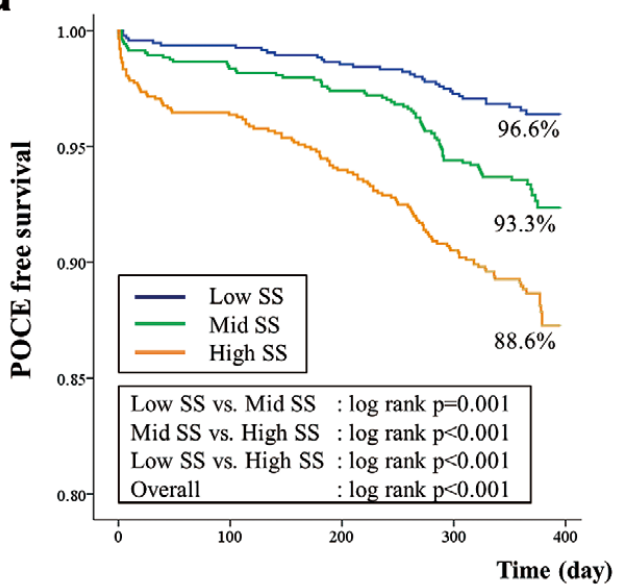

\begin{tabular}{lllll}
\hline No at risk & & & & \\
\hline Low SS & 971 & 952 & 944 & 916 \\
Mid SS & 1053 & 1021 & 1010 & 966 \\
High SS & 1023 & 973 & 949 & 903 \\
\hline
\end{tabular}

b

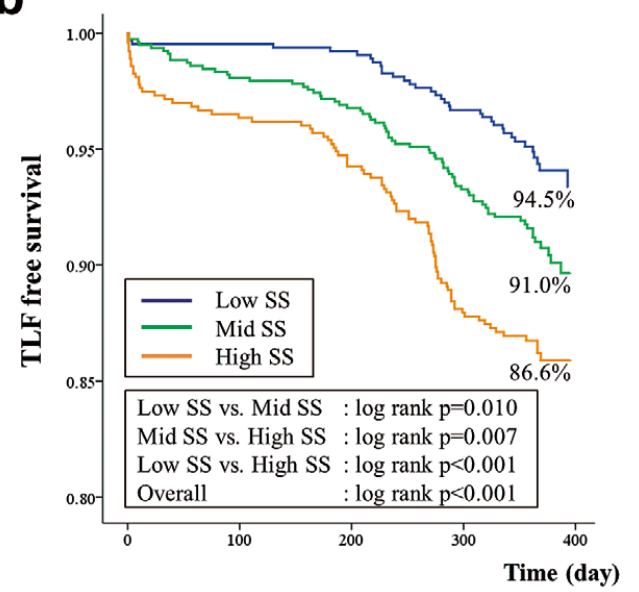

\begin{tabular}{lllll}
\hline No at risk & & & & \\
\hline Low SS & 639 & 631 & 629 & 609 \\
Mid SS & 783 & 760 & 749 & 711 \\
High SS & 633 & 599 & 585 & 541 \\
\hline
\end{tabular}

B

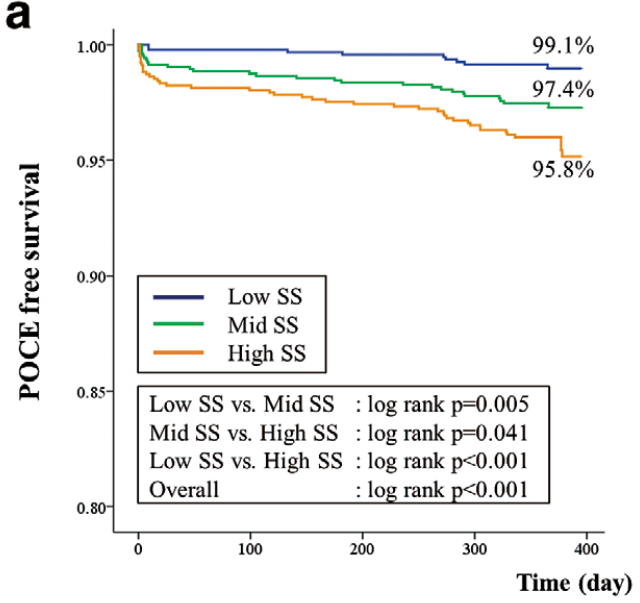

\begin{tabular}{lllll}
\hline No at risk & & & & \\
\hline Low SS & 971 & 955 & 953 & 933 \\
Mid SS & 1053 & 1022 & 1016 & 993 \\
High SS & 1023 & 981 & 971 & 949 \\
\hline
\end{tabular}

b

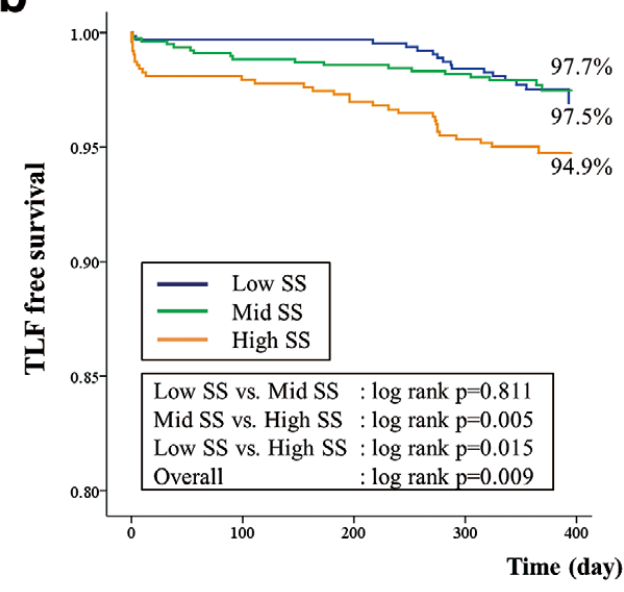

\begin{tabular}{lllll}
\hline No at risk & & & & \\
\hline Low SS & 639 & 632 & 632 & 619 \\
Mid SS & 783 & 764 & 759 & 744 \\
High SS & 633 & 607 & 600 & 583 \\
\hline
\end{tabular}

Figure 2. Kaplan-Meier survival curves in patients with everolimus-eluting stents (A) and Sirolimus-eluting stents (B) for the endpoints of (a) patient-oriented composite endpoint (POCE) and (b) target-lesion failure (TLF). The low-SS (0-8), mid-SS (8-16), and high-SS $(>16)$ groups had a statistically significant increase in the cumulative survival curves for both POCE and TLF. SS, SYNTAX score.

\section{Study Limitations}

First, this was not a randomized study, but rather a retrospective observational registry and therefore the data acquired may not have been scrutinized to the levels expected in randomized studies. However, we performed extensive data collection, and crosschecked the survival of all of the patients with a national population registry that keeps track of the vital status of the patients. Also, the baseline angiography was reviewed and the SS calculated at an independent angiographic core laboratory. Therefore, we believe that there is low likelihood for underreporting of clinical events or bias in the calculation of the SS. Second, the
SS was not only developed to assess the clinical outcomes in patients receiving PCI but also to state whether PCI was appropriate over coronary artery bypass surgery in complex lesions. However, our registry lacked a surgical arm. Therefore, a comparison between PCI with "limus-eluting" stents and bypass surgery for the same tertile of the SS was not possible. Third, there is always the limitation of interobserver and intraobserver variabilities when calculating the $\mathrm{SS} .{ }^{20}$ However, the SS was calculated by expert technicians at an independent angiographic core laboratory, and the correlation was confirmed to be $>95 \%$. 


\section{Conclusions}

The SS and the cSS are useful indices to predict the risk of adverse clinical events in an unrestricted, enriched population of patients receiving PCI with "limus-eluting" stents, including the widely used EES.

\section{Acknowledgments}

We thank the specialists of the Angiographic Core Lab of Seoul National University Hospital for their dedicated efforts in performing the angiographic analysis and scoring.

\section{Funding Sources}

This study was supported by a research grant from the Seoul National University Hospital and grants from the Clinical Research Center for Ischemic Heart Disease, Seoul, Republic of Korea (0412-CR02-07040001) and from the Innovative Research Institute for Cell Therapy, Seoul National University Hospital (A062260), sponsored by the Ministry of Health, Welfare \& Family, Republic of Korea. The authors are solely responsible for the design and conduct of this study, all study analyses and drafting and editing of the paper.

\section{Disclosures}

None.

\section{References}

1. Sianos G, Morel MA, Kappetein AP, Morice MC, Colombo A, Dawkins $\mathrm{K}$, et al. The SYNTAX Score: An angiographic tool grading the complexity of coronary artery disease. EuroIntervention 2005; 1: 219-227.

2. Lemesle G, Bonello L, de Labriolle A, Steinberg DH, Roy P, Pinto Slottow TL, et al. Prognostic value of the Syntax score in patients undergoing coronary artery bypass grafting for three-vessel coronary artery disease. Catheter Cardiovasc Interv 2009; 73: 612-617.

3. Capodanno D, Capranzano P, Di Salvo ME, Caggegi A, Tomasello D, Cincotta G, et al. Usefulness of SYNTAX score to select patients with left main coronary artery disease to be treated with coronary artery bypass graft. JACC Cardiovasc Interv 2009; 2: 731-738.

4. Shiomi H, Tamura T, Niki S, Tada T, Tazaki J, Toma M, et al. Interand intra-observer variability for assessment of the synergy between percutaneous coronary intervention with TAXUS and cardiac surgery (SYNTAX) score and association of the SYNTAX score with clinical outcome in patients undergoing unprotected left main stenting in the real world. Circ J 2011; 75: 1130-1137.

5. Garg S, Sarno G, Girasis C, Vranckx P, de Vries T, Swart M, et al. A patient-level pooled analysis assessing the impact of the SYNTAX (synergy between percutaneous coronary intervention with taxus and cardiac surgery) score on 1-year clinical outcomes in 6,508 patients enrolled in contemporary coronary stent trials. JACC Cardiovasc Interv 2011; 4: 645-653.

6. Garg S, Sarno G, Garcia-Garcia HM, Girasis C, Wykrzykowska J, Dawkins KD, et al. A new tool for the risk stratification of patients with complex coronary artery disease: The Clinical SYNTAX Score. Circ Cardiovasc Interv 2010; 3: 317-326.

7. Capodanno D, Caggegi A, Miano M, Cincotta G, Dipasqua F, Giacchi $\mathrm{G}$, et al. Global risk classification and clinical SYNTAX (synergy between percutaneous coronary intervention with TAXUS and cardiac surgery) score in patients undergoing percutaneous or surgical left main revascularization. JACC Cardiovasc Interv 2011; 4: 287-297.

8. Girasis C, Garg S, Raber L, Sarno G, Morel MA, Garcia-Garcia HM, et al. SYNTAX score and Clinical SYNTAX score as predictors of very long-term clinical outcomes in patients undergoing percutaneous coronary interventions: A substudy of SIRolimus-eluting stent compared with pacliTAXel-eluting stent for coronary revascularization (SIRTAX) trial. Eur Heart J 2011; 32: 3115-3127.

9. Sakakibara T, Ishii H, Toriyama T, Aoyama T, Takahashi H, Kamoi $\mathrm{D}$, et al. Sirolimus-eluting stent vs. everolimus-eluting stent for coronary intervention in patients on chronic hemodialysis. Circ J 2012; 76: $351-355$

10. Wykrzykowska JJ, Garg S, Girasis C, de Vries T, Morel MA, van Es $\mathrm{GA}$, et al. Value of the SYNTAX score for risk assessment in the all- comers population of the randomized multicenter LEADERS (Limus Eluted from A Durable versus ERodable Stent coating) trial. $J \mathrm{Am}$ Coll Cardiol 2010; 56: 272-277.

11. Cutlip DE, Windecker S, Mehran R, Boam A, Cohen DJ, van Es GA, et al. Clinical end points in coronary stent trials: A case for standardized definitions. Circulation 2007; 115: 2344-2351.

12. Serruys PW, Onuma Y, Garg S, Vranckx P, De Bruyne B, Morice MC, et al. 5-year clinical outcomes of the ARTS II (Arterial Revascularization Therapies Study II) of the sirolimus-eluting stent in the treatment of patients with multivessel de novo coronary artery lesions. $J$ Am Coll Cardiol 2010; 55: 1093-1101.

13. Kim YH, Park DW, Kim WJ, Lee JY, Yun SC, Kang SJ, et al. Validation of SYNTAX (Synergy between PCI with Taxus and Cardiac Surgery) score for prediction of outcomes after unprotected left main coronary revascularization. JACC Cardiovasc Interv 2010; 3: 612623.

14. Garg S, Serruys PW, Silber S, Wykrzykowska J, van Geuns RJ, Richardt $\mathrm{G}$, et al. The prognostic utility of the SYNTAX score on 1-year outcomes after revascularization with zotarolimus- and everolimus-eluting stents: A substudy of the RESOLUTE All Comers Trial. JACC Cardiovasc Interv 2011; 4: 432-441.

15. Capodanno D, Miano M, Cincotta G, Caggegi A, Ruperto C, Bucalo $\mathrm{R}$, et al. EuroSCORE refines the predictive ability of SYNTAX score in patients undergoing left main percutaneous coronary intervention. Am Heart J 2010; 159: 103-109.

16. Farooq V, Brugaletta S, Serruys PW. Contemporary and evolving risk scoring algorithms for percutaneous coronary intervention. Heart 2011; 97: $1902-1913$.

17. Ranucci M, Castelvecchio S, Menicanti L, Frigiola A, Pelissero G. Risk of assessing mortality risk in elective cardiac operations: Age, creatinine, ejection fraction, and the law of parsimony. Circulation 2009; 119: 3053-3061.

18. Park DW, Park SW, Park KH, Lee BK, Kim YH, Lee CW, et al. Frequency of and risk factors for stent thrombosis after drug-eluting stent implantation during long-term follow-up. Am J Cardiol 2006; 98: $352-356$.

19. Kimura T, Morimoto T, Natsuaki M, Shiomi H, Igarashi K, Kadota K, et al. Comparison of everolimus-eluting and sirolimus-eluting coronary stents: 1-year outcomes from the Randomized Evaluation of Sirolimuseluting Versus Everolimus-eluting stent Trial (RESET). Circulation 2012; 126: $1225-1236$

20. Genereux P, Palmerini T, Caixeta A, Cristea E, Mehran R, Sanchez R, et al. SYNTAX score reproducibility and variability between interventional cardiologists, core laboratory technicians, and quantitative coronary measurements. Circ Cardiovasc Interv 2011; 4: 553-561.

\section{Supplementary Files}

Supplementary File 1

Appendix S1. Extended description of study methods

Table S1. Baseline clinical characteristics of the total population

Table S2. Baseline lesion characteristics of the total population

Table S3. Area under the curve for SYNTAX score (SS) and clinical SYNTAX score (cSS)

Table S4. Clinical outcomes at 1-year according to SYNTAX tertile in everolimus-eluting stent and sirolimus-eluting stent groups

Table S5. Clinical outcomes at 1-year according to allocated stent

Table S6. Baseline characteristics of patients after propensity-score matching in the $\mathrm{SS}<8$ tertile

Table S7. Baseline characteristics of patients after propensity-score matching in the $8 \leq \mathrm{SS} \leq 16$ tertile

Table S8. Baseline characteristics of patients after propensity-score matching in the SS $>16$ tertile

Table S9. Clinical outcomes according to allocated stent in each propensity-score matched group

Figure S1. Kaplan-Meier survival curves of the propensity-score matched patients.

Please find supplementary file(s);

http://dx.doi.org/10.1253/circj.CJ-13-0645 